九州大学学術情報リポジトリ

Kyushu University Institutional Repository

\title{
Changes in Social and Spacing Behaviour of Japanese Black Cattle after Introducing a Strange Cow into a Stable Herd
}

Nakanishi, Yoshitaka

Kuju Agricultural Research Center, Kyushu University

Mutoh, Yoshihiro

Kuju Agricultural Research Center, Kyushu University

Umetsu, Raizaburo

Kuju Agricultural Research Center, Kyushu University

Masuda, Yasuhisa

Department of Animal Science, Faculty of Agriculture, Kyushu University

他

https://doi.org/10.5109/23962

出版情報 : 九州大学大学院農学研究院紀要. 36 (1/2)，pp.1-11，1991-10. Kyushu University バージョン：

権利関係 : 


\title{
Changes in Social and Spacing Behaviour of J apanese Black Cattle after Introducing a Strange Cow into a Stable Herd
}

\author{
Yoshitaka Nakanishi, Yoshihiro Mutoh*, Raizaburo Umetsu, \\ Yasuhisa Masuda** and Ichiro Goto** \\ Kuju Agricultural Research Center, Kyushu University, \\ Kuju-cho, Oita 878-02, Japan \\ **Department of Animal Science, Faculty of Agriculture, \\ Kyushu University, Fukuoka 812, Japan
}

(Received February 15, 1991)

\begin{abstract}
Social and spacing behaviour of Japanese Black Cattle in a stable herd (8 animals) as affected by introducing a strange cow were investigated in a dry-lot. Before and after introducing the strange cow, frequency of agonistic encounters and social licking, and positions of all animals in lying in the herd were recorded between 0930 and $1730 \mathrm{~h}$ on each observation day. Introducing the 'strange cow into the herd initially caused a remarkable increase (about 4 fold) in agonistic encounters on the day of introduction, thereafter agonistic encounters tended to decrease and on 7th day return to former lower level. Social licking pattern showed a reciprocal trend to agonistic behaviour pattern, indicating a significant correlation between social licking interactions and $1 /$ (physical agonistic encounters) $\left(R^{2}=0.85\right)$. Dominance order in the herd on the day of introduction was relatively constant afterwards. The mean distance to nearest neighbor in the herd revealed no great variation among observation days, however the mean distance from individual to others and the area occupied by the group showed higher values after introduction than before. The newly introduced cow suffered relatively great weight loss compared with the others during the period of observation.
\end{abstract}

\section{INTRODUCTION}

In a cattle herd management, effect of management practices on the frequency and intensity of agonistic interactions is one of the most important considerations. Reducing space or crowding tends to increase agonistic encounters among groupmates and at higher population density, subordinates are forced to invade the personal space of their neighbors (Donaldson et al., 1972 ; Kondo et al., 1984b). By contrast, grouping unfamiliar cows, exchanging animals between herds or introducing a strange animal into a stable herd, inevitably causes an increase in aggression and imposes certain stress on subordinate animals (Lamb, 1976). Under intensive livestock production systems, information on space and sociality is extremely important (Squires, 1975). Southwick (1966) also showed that changing social structure within a group had a stronger impact on aggression compared with reducing space or crowding. Therefore, in order to alleviate conflicts among individuals, social rather than spatial considerations may be a matter of great importance, as pointed out by Kiley-Worthington

*Present address: Meijiya Sangyo Co., LTD., Nougata-shi, Fukuoka 822, Japan 
(1977). It is well known that when a new animal is introduced into a herd the frequency of agonistic encounters is high at first until dominance-subordination relationships are established and then it decreases gradually (Price, 1980 ; Curtis, 1983). However, little information is available on the changes in social and spacing behaviour of Japanese Black Cattle before and after introducing a strange cow into a stable herd.

In the present study with Japanese Black Cattle, social and spatial structures in a stable small herd were examined, and then the effects of introducing a strange cow into the herd on their social and spacing behaviour were investigated.

\section{MATERIALS AND METHODS}

This study was conducted at experimental dry-lot in Kuju Agricultural Research Center (alt. $950 \mathrm{~m}$ ) of Kyushu University from $16 / 9$ to $27 / 9$ in 1988 . Data on rainy days $(19 / 9,21 / 9$ and $24 / 9)$ were not recorded.

\section{Animals and management}

A total of 9 horned Japanese Black Cattle were used for this study. The herd of 8 animals was composed of 7 cows and a heifer, and all animals had been kept together since $3 / 9$ in 1988. One cow (a strange cow) kept in another group (cow-calf group) was introduced into the stable herd of 8 animals at her calf's weaning on 20/9. The profile of experimental cattle was listed in Table 1. Experimental dry-lot $\left(225 \mathrm{~m}^{2}\right)$ was surrounded with iron fences of 1.4-m high, and, the floor was flatly concreted (Fig. 1). The animals received $2.5 \mathrm{~kg} / \mathrm{head}$ of hay cube per day at $0900 \mathrm{~h}$ during experimental period. Baled rice straw (supply at $1530 \mathrm{~h}$ ), water and salt were given ad libitum.

\section{Observations}

Cattle were easily identified by dyed numbers on their sides. After observation of social and spacing behaviour of the existing herd (8 animals) on $17 / 9$ and $18 / 9$, the behaviour of 9 animals including a newly introduced cow was observed on 20/9,22/9, $23 / 9,25 / 9$ and $26 / 9$.

Table 1. Profile of experimental cattle.

\begin{tabular}{ccccc}
\hline Cattle No. & Age (mo.) & Body weight $(\mathrm{kg})$ & Withers height $(\mathrm{cm})$ & Seniority \\
1 & 87 & 419 & 127 & 6 \\
10 & 74 & 559 & 132 & 1 \\
14 & 110 & 462 & 127 & 4 \\
17 & 45 & 474 & 128 & 5 \\
21 & 47 & 393 & 128 & 8 \\
22 & 34 & 408 & 128 & 7 \\
23 & 34 & 391 & 129 & 2 \\
9 & 34 & 505 & 134 & 9 \\
\hline
\end{tabular}

'Rank 1 indicates the greatest length of a membership in the herd.

*Newly introduced cow. 


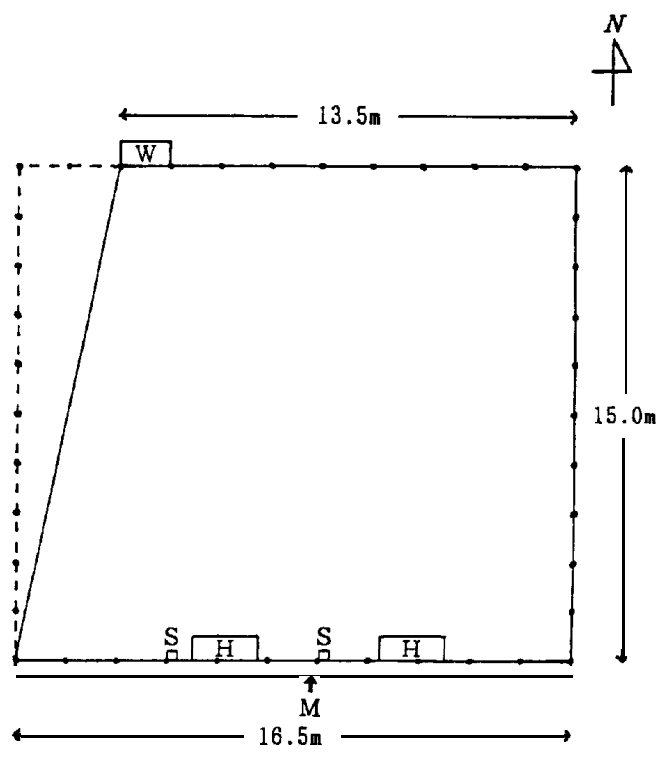

Fig. 1. Schematic diagram of experimental dry-lot.

W : Water, H : Hay rack, M : Manger with stanchion, S: Salt,

Colored pole

\section{(1) Social behaviour}

Agonistic encounters among individuals were divided into four major categories ; fighting, butting, threatening and avoiding, as defined by Hafez and Bouissou (1975), and the frequency between 0930 and $1730 \mathrm{~h}$ was recorded on each observation day. The number of social licking was also recorded.

(2) Dominance order

From the outcome of agonistic interactions, cattle were scored for their dominance order from highest to lowest on the ratio of wins to total encounters. The animals were weighed on $16 / 9$ and $27 / 9$, and their withers height, body length and heart girth were measured on $16 / 9$ to calculate the correlations with dominance order. Seniority expressed as length of a membership in the herd and the relative frequency of actively aggressive encounters (butting, fighting and threatening) as an indicator of animal's aggressiveness, were also used to examine their relations to dominance order.

(3) Spacing behaviour

Corral was marked by means of colored poles at intervals of $1.5-\mathrm{m}$. The positions where all cattle were lying together were observed at 15-min. intervals throughout the experiment. The position of each animal was determined by regarding lot floor as the grid $(10 \times 11$ squares, each $1.5 \times 1.5 \mathrm{~m})$, and plotted into recording sheets which expressed as $\mathrm{X}-\mathrm{Y}$ coordinates (Fig. 1). The mean distance to nearest neighbor $\left(\overline{\mathrm{r}}_{\mathrm{A}}\right)$ and the mean distance from individual to others (D) in the group were calculated. In addition, the area occupied by the group (OA) was estimated according to the method of Kondo et al. (1984a). 


\section{Data analyses}

For statistical analysis of the behavioural data Spearman's rank correlation coefficient, Kendall's coefficient of concordance and regression analysis were used (Siegel, 1956 ; Snedecor and Cochran, 1967).

\section{RESULTS AND DISCUSSION}

\section{Social hierarchy in the existing herd}

The coefficient of Spearman's rank correlation in dominance order between $17 / 9$ and $18 / 9$ was statistically significant $\left(r_{\mathrm{s}}=0.935, P<0.01\right)$, so that dominance order in this herd was thought to be basically consistent between days. This result strongly reflected the evidence of Dickson et al. (1967) who indicated that dominance order was stable over a period of time because of high repeatability for dominance order of 0.97 from day to day.

Table 2 shows coefficients of Spearman's rank correlation between dominance order (pooled data of Z-day observations) and such variables as age, body size, seniority and aggressiveness.

There were statistically significant positive correlations between dominance order (DO) and body weight $\left(r_{\mathrm{s}}=0.839, P<0.05\right)$, DO and heart girth $\left(r_{\mathrm{s}}=0.911, P<0.01\right)$, DO and seniority $\left(r_{\mathrm{s}}=0.815, P<0.05\right)$, respectively. Thus, in this herd heavier animals with larger heart girth tended to be more dominant. However, the dominance order showed no significant relation to age. Wagnon (1965) and Reinhardt and Reinhardt (1975) suggested that growing age led to a decline in social dominance, because they found quadratic regression between dominance order and age in a herd with wide range of age. Seniority was of great significance in achieving dominance for social status, as might be expected from previous studies (Schein and Fohrman, 1955 ; Guhl and Atkeson, 1959). Wagnon (1965) and Collis (1976) obtained significantly positive correlation between dominance rank and aggressiveness in a herd. By contrast, Reinhardt and Reinhardt (1975) stated that aggressiveness in cattle was not a mean by which dominance for social status could be achieved. There had been no conclusive evidence that cattle with higher level of aggression could attain greater social dominance. This study showed that there was no definite correlation between dominance order and aggressiveness in the herd, although the most aggressive cow was the most dominant

Table 2. Coefficients of Spearman's rank correlation $\left(r_{\mathrm{s}}\right)$ between dominance order and variables $(n=8)$.

\begin{tabular}{lcc}
\hline Variable & $r_{\mathrm{s}}$ & Significance level \\
\hline Age & 0.399 & \\
Body weight & 0.839 & $P$ co.05 \\
Withers height & 0.244 & $P$ co.01 \\
Heart girth & 0.911 & \\
Body length & 0.720 & $P<0.05$ \\
Seniority & 0.815 & \\
Aggressiveness & 0.530 & \\
\hline
\end{tabular}


animal (Cattle 23) and the least aggressive animal was the least dominant one (Cattle 22).

\section{Change in social behaviour of cattle after introducing a strange cow into the stable herd}

The frequency of categorized agonistic encounters in the herd before and after introducing a strange cow is shown in Table 3.

Before introducing the strange cow (Cattle 9), the frequency of agonistic encounters showed 129 and 180 times on $17 / 9$ and 18/9, respectively. Introduction of the strange cow into the herd initially caused about 4-fold increase (610 times) in agonistic encounters, then the frequency tended to decrease and on $26 / 9$ eventually approached to the former lower level (129 times). Physical contacts (fighting and butting) and non-physical contacts (threatening and avoiding) among individuals showed the highest values on the day when the strange cow was introduced, thereafter tended to decline. Moreover, physical and aggressive forms of agonistic interactions revealed larger values on 1-3rd day after introduction than before. It was noteworthy that the newly introduced cow (Cattle 9) showed the highest value (50 times) of actively aggressive encounters within the group on 1st day (Table 4). This pattern of high frequency in aggression caused by Cattle 9 lasted for 4-5 days. The intensity of actively aggressive behaviour of the strange cow may attribute largely to the integration of two behavioural types. One is the exploratory (or investigative) behaviour that the introduced cow investigates her unfamiliar surroundings and her groupmates in an attempt to establish her appropriate position in dominance order of new group. The other is the behavioural symptom of frustration (a kind of maternal aggression toward person or animal that deprived dam of her offspring) as a result of separation of mother cow and her calf at weaning. Therefore, it is suggested that "displacement behaviour"(Hurnik et al., 1985) consisting of the above two activities, induced more reinforced aggression of the introduced cow than the others.

Table 3. Frequency of categorized agonistic behaviour.

\begin{tabular}{lrrrrrrr}
\hline & \multicolumn{7}{c}{ Date } \\
Item & $17 / 9$ & $18 / 9$ & $20 / 9^{*}$ & $22 / 9$ & $23 / 9$ & $25 / 9$ & $26 / 9$ \\
\hline Fighting (no.) & 0 & 0 & 2 & 0 & 0 & 0 & 0 \\
Butting (no.) & 0 & 5 & 27 & 12 & 16 & 9 & 5 \\
Threatening (no.) & 24 & 35 & 114 & 87 & 50 & 57 & 17 \\
Avoiding (no.) & 105 & 140 & 467 & 244 & 418 & 273 & 107 \\
Total (no.) & 129 & 180 & 610 & 343 & 484 & 339 & 129 \\
Physical form $(\%)^{3}$ & 0 & 2.8 & 4.8 & 3.5 & 3.3 & 2.7 & 3.9 \\
Aggressive form $(\%)^{4}$ & 18.6 & 22.2 & 23.4 & 28.9 & 13.6 & 19.5 & 17.1 \\
\hline
\end{tabular}

"Day when a strange cow was introduced into the herd.

'Physical contacts.

'Non-physical contacts.

${ }^{3}$ Proportion of physical contacts to total agonistic encounters.

${ }^{4}$ Proportion of physical contacts and the number of threatening to total agonistic encounters. 
Social licking pattern of cattle is shown in Fig. 2.

Cattle had lower level of social licking interactions on the day of introducing the strange cow than before introduction. Thereafter, the frequency of social licking tended to increase and return to the former higher level. Social licking is thought to be one of affiliative relationships (Hart, 1985) and to be an important behaviour leading to psychological stability of herdmates (Sato, 1984). In addition, Arave and Albright (1981) pointed out that social grooming (licking) was of particular importance in establishing and maintaining social structure of a herd. The inverse trend to the

Table 4. Number of actively aggressive encounters (fighting, butting and threatening) of each cattle on each observation day after introducing a strange cow into the stable herd.

\begin{tabular}{rrrrrrrrrr}
\hline & \multicolumn{10}{c}{ Cattle No. } \\
\cline { 2 - 10 } Date & 1 & 7 & 10 & 14 & 17 & 21 & 22 & 23 & $9^{*}$ \\
& 6 & 10 & 12 & 4 & 31 & 2 & 0 & 26 & 50 \\
$20 / 9$ & 6 & 3 & 3 & 3 & 15 & 11 & 0 & 14 & 44 \\
$22 / 9$ & 2 & 5 & 9 & 3 & 8 & 4 & 0 & 10 & 25 \\
$23 / 9$ & 2 & 9 & 8 & 5 & 19 & 2 & 0 & 12 & 9 \\
$25 / 9$ & 3 & 4 & 0 & 1 & 3 & 2 & 0 & 7 & 2 \\
$26 / 9$ & & & &
\end{tabular}

*Newly introduced cow.

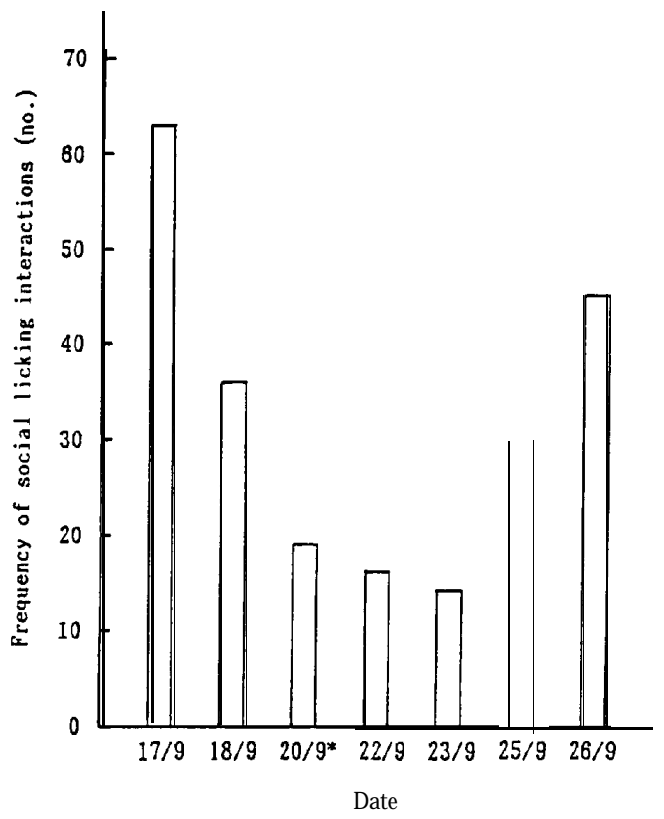

Fig. 2. Frequency of social licking interactions in the herd.

*Day when a strange cow was introduced into the stable herd. 
pattern of agonistic behaviour in this study suggested that social licking pattern of cattle functioned as an activity leading to social stability of the herd.

As mentioned above, some relationship was suggested between agonistic and social licking behaviour of cattle after introducing the strange cow. The relationship between the two was reciprocal, as shown in Fig. 3. Correlation of social licking interactions with $1 /$ (total number of agonistic encounters) was significant $(r=0.903, P$ $<0.05)$ and its regression equation obtained was :

$$
Y_{\mathrm{L}}=8.439+4722.49 / X_{\mathrm{TA}}
$$

where $\quad X_{\mathrm{TA}}=$ total number of agonistic encounters ; physical and non-physical contacts (no.)

$Y_{\mathrm{L}}=$ social licking interactions (no.)

The relationship between social licking interactions and the number of physical contacts in agonistic encounters was also reciprocal (Fig. 4) with a significant correlation $(r=0.922, P<0.05)$ between social licking interactions and $1 /$ (the number of physical agonistic encounters). The relationship was presented in the following regression equation :

$$
\begin{aligned}
& Y_{\mathrm{L}}=6.411+187.09 / X_{\mathrm{PA}} \\
& \text { where } X_{\mathrm{PA}}=\text { number of physical agonistic encounters ; fighting and butting } \\
& \text { (no.) } \\
& Y_{\mathrm{L}}=\text { social licking interactions (no.) }
\end{aligned}
$$

Thus, after introducing a strange cow, the social licking interactions in the herd tended to increase as the frequency of agonistic encounters decreased. Additionally social licking interactions showed a closer correlation with physical agonistic encounters than total agonistic encounters. The reciprocal relationships between agonistic and social licking behaviour obtained in this study theoretically support the suggestion of Reinhardt (1980) who points out that social grooming (licking) is a friendly behaviour which counterbalances agonistic interactions.

\section{Change in dominance order in cattle after introducing a strange cow into the}

\section{stable herd}

Table 5 shows dominance order determined from agonistic behaviour in the herd before and after introducing a strange cow. Though data on social position of the introduced cow (Cattle 9) in her previous group (cow-calf group) were not presented

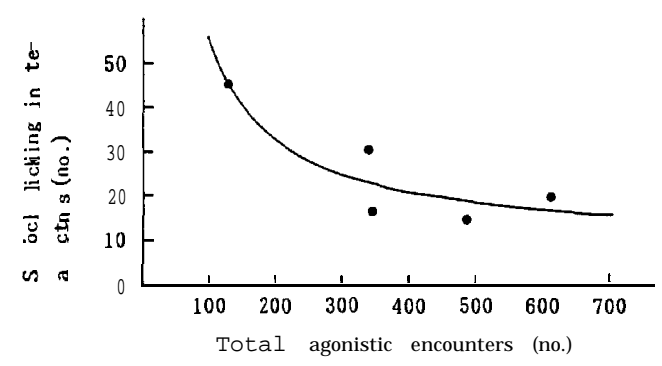

Fig. 3. Relationship of social licking interactions to total number of agonistic encounters in cattle after introducing a strange cow into the stable herd. 
herein, she was dominant within the group composing of 2 cow-calf pairs. Before introducing the strange cow, Cattle 23 ranked highest in the herd during the period of observation, though it was dominated by Cattle 14 only. The introduction of the strange cow (Cattle 9) changed linear-tending hierarchy containing some triangular relationships into more complex hierarchy. In a new herd, Cattle 9 had the precedence over Cattle 23, however Cattle 9 dominated by 4 animals (Cattle 1, 7, 10 and 14) ranked

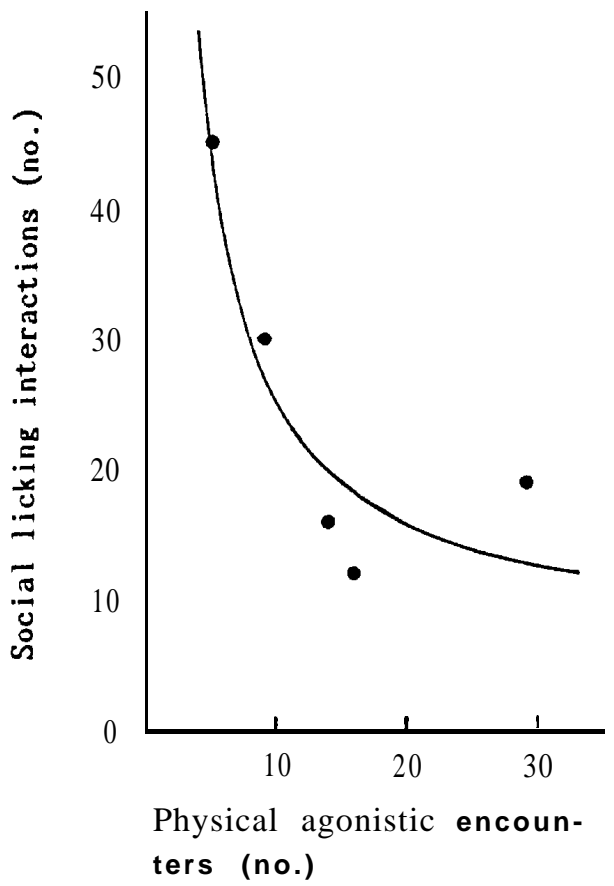

Fig. 4. Relationship of social licking interactions to the number of physical agonistic encounters in cattle after introducing a strange cow into the stable herd.

Table 5. Dominance order determined from agonistic behaviour before and after introducing a strange cow into the stable herd.

\begin{tabular}{|c|c|c|c|c|c|c|c|c|c|}
\hline \multirow{2}{*}{ Dominance order } & \multicolumn{9}{|c|}{ Cattle No. } \\
\hline & 1 & 7 & 10 & 14 & 17 & 21 & 22 & 23 & $9^{*}$ \\
\hline Order A' & 4 & 2 & 3 & 5 & 5 & 7 & 8 & 1 & \\
\hline Order $\mathrm{B}^{2}$ & 4 & 1 & 2 & 4 & 7 & 8 & 9 & 2 & 4 \\
\hline
\end{tabular}

* Newly introduced cow.

'Calculated form 2-day observation (pooled data of $17 / 9$ and $18 / 9$ ).

${ }^{2}$ Calculated from 5-day observation (pooled data of 20/9,22/9,23/9,25/9 and 26/9).

Kendall's coefficient of concordance $(W)$ among 5 observations after introduction of a strange cow was $0.966(\mathrm{P}<0.001)$. 
middle in the herd and Cattle 23 became second ranking animal. On the contrary, dominance order of lower ranking animals (Cattle 21 and 22) was not changed by the introduction of the strange cow. After introduction, Kendall's coefficient of concordance $(W)$ among dominance orders for 5 observation days was statistically significant ( $W=0.966, P<0.001$ ). Therefore, the dominance order determined on the day of introducing the strange cow appeared to be relatively constant afterwards. This indicated that social status of newly introduced cow was established in earlier atage (just one day), which agreed with the report of Hafez and Bouissou (1975) who described that dominance rank was determined for most cows in a short period (1 hr) when a strange animal was introduced into an established herd.

\section{Change in spacing behaviour of cattle after introducing a strange cow into the stable herd}

Table 6 shows the mean distance to nearest neighbor $\left(\overline{\mathrm{r}}_{\mathrm{A}}\right)$, the mean distance from individual to others (D) and the area occupied by the herd (OA) calculated from the positions of all cattle in lying before and after introducing a strange cow.

In this study, lying behaviour of all cattle was observed on $17 / 9,18 / 9,23 / 9,25 / 9$ and 26/9. The $\vec{r}_{A}$, which reflected the mean of personal distances (Hediger, 1955) in the herd, ranged from 2.1 to $2.8 \mathrm{~m}$ and it showed no remarkable variation during the days of observation. The result obtained from beef cattle in this study was similar to finding by Kondo (1987) who reported that the $\overline{\mathrm{r}}_{\mathrm{A}}$ of lying dairy cows in a dry-lot was about $2.2 \mathrm{~m}$. The D and OA, which implied a measure (Hediger, 1955) and another measure (Kondo et al., 1984a) of social distances, respectively, were affected by introducing the strange cow into the herd. These parameters reveald higher values after introduction than before. The value of OA markedly decreased until 26/9 after introduction.

\section{Livew eight change in cattle after introducing a strange cow into the stable herd}

Table 7 shows liveweight change in cattle throughout the experimental period.

There was some variation in weight gain among animals after introducing a

Table 6. Mean distance to nearest neighbor $\left(\overline{\mathrm{r}}_{\mathrm{A}}\right)$, mean distance from individual to others (D) and area occupied by the herd $(\mathrm{OA})$ calculated from the positions of all cattle in lying before and after introducing a strange cow into the stable herd.

\begin{tabular}{lrrlrrrr}
\hline & \multicolumn{7}{c}{ Date } \\
\cline { 2 - 8 } Item & \multicolumn{1}{c}{$17 / 9$} & $18 / 9$ & $20 / 9^{*}$ & $22 / 9$ & $23 / 9$ & $25 / 9$ & $26 / 9$ \\
\hline $\mathrm{r}_{\mathrm{A}}(\mathrm{m})$ & $2.1(5)$ & $2.6(2)$ & $-\mathrm{a}$ & & $2.6(2)$ & $2.8(7)$ & $2.6(7)$ \\
$\mathrm{D}(\mathrm{m})$ & $5.5(5)$ & $5.4(2)$ & - & & $8.3(2)$ & $6.1(7)$ & $6.5(7)$ \\
$\mathrm{OA}\left(\mathrm{m}^{2}\right)$ & $28.7(5)$ & $26.1(2)$ & - & & $93.9(2)$ & $43.8(7)$ & $37.6(7)$ \\
\hline
\end{tabular}

*Day when a strange cow was introduced into the herd.

"Lying behaviour of all cattle was not observed on $20 / 9$ and 22/9.

Figure in the parenthesis indicates the times of lying observed at 15-min. intervals during the period of observation. 
Table 7. Liveweight change (for 11 days) in cattle as affected by introducing a strange cow into the stable herd.

\begin{tabular}{lllllllllll}
\hline & \multicolumn{10}{c}{ Cattle No. } \\
\cline { 2 - 11 } & 1 & 7 & 10 & 14 & 17 & 21 & 22 & 23 & $9^{*}$ \\
\hline Weight gain $(\mathrm{kg})$ & 4 & 4 & 2 & -2 & 6 & -3 & -4 & -8 & -13 \\
\hline
\end{tabular}

*Newly introduced cow.

strange cow (Cattle 9), especially she had a weight loss of $13 \mathrm{~kg}$ for 11 days. Schein and Fohrman (1955) reported that introduction of new cows into an established herd led to a decrease in milk yield of a new herd. In the present study, adding a strange cow to a stable herd affected mean weight gain of a new herd more or less, and it had a negative effect on productive performance of the highest ranking animal (Cattle 23) in the existing herd as well as the newly introduced cow. This result may reflect that change in group structure followed by introducing a strange cow imposed certain stress not only on the newly introduced animal but also on the most dominant animal in the existing herd.

In conclusion, when a strange cow was introduced into a stable herd (8 cattle), the dominance order of new herd was apparently established on the day of introduction and social structure of the herd tended to become stable on 7 th day.

\section{ACKNOWLEDGEMENTS}

The authors wish to thank Mr. T. Etoh of Kuju Agricultural Research Center, Kyushu University and Mr. T. Shiraishi for their skilled technical assistance and care of experimental animals in this study.

\section{REFERENCES}

Arave, C. W. and J. L. Albright 1981 Cattle behavior. J. Dairy Sci., 64 : 1318-1329

Collis, K. A. 1976 An investigation of factors related to the dominance order of a herd of dairy cows of similar age and breed. Appl. Anim. Ethol., 2: 167-173

Curtis, S. E. 1983 Environmental Management in Animal Agriculture. Iowa State Univ. Press, Ames, Iowa (United States), pp. 183-191

Dickson, D. P., G. R. Barr and D. A. Wieckert 1967 Social relationship of dairy cows in a feed lot. Behaviour, $29: 195-203$

Donaldson, S. L., J. L. Albright and M. A. Ross 1972 Space and conflict in cattle. Proc.Ind.Acad.Sci., 81: $352-354$

Guhl, A. M. and F. W. Atkeson 1959 Social organization in a herd of dairy cows. Trans. Kans. Acad. Sci., $62: 80-87$

Hafez,E. S. E. and M. F. Bouissou 1975 The behaviour of cattle. In "The Behaviour of Domestic Animals", ed. by E. S. E. Hafez, Baillière Tindall, London, pp. 203-245

Hart, B. L. 1985 The Behavior of Domestic Animals. W. H. Freeman \& Company, New York (United States), pp. $15^{-81}$

Hediger, II. 1955 Studies of the Psychology and Behaviour of Captive Animals in Zoos and Circuses. 
Transl. by B. A. Geoffrey Sircom, Butterworths Scientific Publications, London pp. 83

Hurnik, J. F., A. B. Webster and P. B. Siegel 1985 Dictionary of Farm Animal Behaviour. University of Guelph, Guelph, Ontario (Canada), pp. 176

Kiley-Worthington, M. 1977 Behavioural Problems of Farm Animals, Oriel Press, Stockfield, London (England), pp. 15-17

Kondo, S. 1987 Behavioral adaptation in group of cattle. Mem.Fac.Agr., Hokkaido Univ., 15 : $192-$ 233 (in Japanese with English summary)

Kondo, S., N. Kawakami, H. Kohama and S. Nishino 1984a Changes in activity, spatial pattern and social behaviour in calves after grouping. Appl.Anim. Ethol., 11: 217-228

Kondo, S., H. Maruguchi and S. Nishino $1984 \mathrm{~b}$ Spatial and social behaviour of calves in reduced drylot space. Jpn. J.Zootech.Sci., 55 : 885-891

Lamb, R. C. 1976 Relationship between cow behavior patterns and management systems to reduce stress. J. Dairy Sci., 59: 1630-1636

Price, E. 0.1980 The behavior of domestic animals. In "Animal Agriculture", ed. by H. H. Cole and W. N. Garrett, W. H. Freeman and Company, San Francisco, pp. 477-495

Reinhardt, V. 1980 Social behaviour of Bos indicus. In "Behaviour in Relation to Reproduction, Management and Welfare of Farm Animals", ed. by M. Wodzicka-Tomaszewska, T. N. Edey and J. J Lynch, University of New England, Armidale, N. S. W., pp. 153-156

Reinhardt, V. and A. Reinhardt 1975 Dynamics of social hierarchy in a dairy herd. Z.Tierpsychol., 38 : 315-323

Sato, S. 1984 Social licking pattern and its relationship to social dominance and live weight gain in weaned calves. Appl. Anim. Behav. Sci., 12: 25-32

Schein, M. W. and M. H. Fohrman 1955 Social dominance relationships in a herd of dairy cattle. $B Y$. J. Anim. Behav., $3: 45-55$

Siegel, S. 1956 Nonparametric Statistics for the Behavioural Sciences. McGraw-Hill Book Co., Inc., New York (United States)

Snedecor, G. W. and W. G. Cochran 1967 Statistical Methods, iowa State Univ. Press, Ames, Iowa (United States)

Southwick, C. H. 1966 An experimental study of intra-group agonistic behaviour in rhesus monkeys (Macaca mulatta). Behaviour, $28: 1822209$

Squires, V. R. 1975 Social behaviour in domestic livestock : the basis for improved animal husbandry. Appl.Anim. Ethol., 1 : 177-184

Wagnon, K. A. 1965 Social dominance in range cows and its effect on supplemental feeding. Calif. Agric. Exp. Stn. Bull. No. 819 